\title{
FOCUS GROUPS AND PRIME MINISTERS' CHIEFS OF STAFF
}

\section{Introduction}

In the USA, the job of the President's Chief of Staff (from now on CoS) is characterised as 'javelin catcher'. In Australia, they have been called 'pest controllers' and 'shock absorbers'. All are vivid metaphors for a job that is carried out far from the public eye in the shadows of politics. These men and women are the hub of a court or network that supports prime ministers (Rhodes 2013). They are the pivotal point at which the political and the administrative meet. It is a private web. Apart from the occasional interview or public lecture little is known about them or their work. So, how do we find out what they and how they do it?

This paper discusses the contribution of focus groups to accessing the innermost reaches of government. It seeks to identify the advantages and disadvantages of using focus groups in political and administrative ethnography. It illustrates the discussion with the case of focus group research conducted with a cohort of 11 individuals who held the position of Chief of Staff $(\mathrm{CoS})$ to the Prime Minister of Australia. Our project examined the work of $\mathrm{CoS}$ who served prime ministers from Malcolm Fraser to Kevin Rudd. We collected their stories - the institutional memory - of a previously unexamined part of the system of advice and support to Australian political leaders. Those readers interested in Australian government - the 'geek' element as one reviewer put it - should seek out Rhodes and Tiernan (2014a and 2014b). Here, we focus on the usefulness of focus groups in elite ethnography.

This paper outlines the current state of political and administrative ethnography in political science and public administration before suggesting that focus groups are a useful tool in the study of governing elites. Briefly we describe the job of prime ministers' CoS before 
explaining our research design, the preparations for the focus group sessions, and the strategies used to manage the dynamics of a diverse group that included former political enemies and factional rivals. We outline our approach to analysis and interpretation before reviewing the strengths and weaknesses of focus groups for research into political and administrative elites. To be clear, we do not report our findings (see Rhodes and Tiernan 2014a); or discuss our theory (see Bevir and Rhodes 2003 and 2006). We offer a commentary on one (not all) of our methods; that is, on focus groups.

\section{Political and administrative ethnography}

Ethnography was traditionally the province of cultural anthropologists, but it has significant potential for political scientists (see Rhodes 2015). Although as Hammersley and Atkinson (2007: 2) note, it 'does not have a standard, well-defined meaning', some words and phrases recur. The ethnographer studies people's everyday lives. The aim is to recover the meaning of their actions. By long association, meaning is captured by participant observation; the defining method of ethnography. Participant observation typically involves fieldwork or deep immersion, whether looking at a Congressional district, a government department or a tribe in Africa.

Until recently, there was little political ethnography by political scientists. For example, Auyer and Joseph's (2007: 2) review of 1,000 articles published in the American Journal of Political Science and the American Political Science Review between 1996 and 2005 found that 'only one article relies on ethnography as a data-production technique'. If it is possible, there is even less administrative ethnography. As Auyero and Joseph (2007: 2) conclude there is a 'double absence'. There is little public administration in the ethnographic literature and even less ethnography in the study of public administration. ${ }^{1}$ 
Nowadays, however, ethnography is no longer defined by participant observation. It has become a diverse and disparate set of practices. Ethnographers deploy a broad toolkit of research methods, analogous to quilt making, montage, or bricolage - 'a pieced together set of representations that are fitted to the specifics of a complex situation' (Denzin and Lincoln 2011: 4). The classic intensive fieldwork study is supplemented by hit-and-run ethnography. So, we ‘study-up’, and ‘follow through’ by conducting ‘yo-yo-research’ in ‘contact zones’ and multilocal sites. These several shorthand expressions can be explained easily. 'Studying-up’ refers to the study of elites not police officers, social workers, and teachers. 'Studying through' refers to following events such as making a policy through the 'webs and relations between actors, institutions and discourses across time and space' (Shore and Wright 1997: 14). 'YoYo research' refers to both regular movement in and out of the field and to participant observation in many local sites (Wulff 2002). A ‘contact zone’ is the “space”, such as a museum, in which peoples geographically and historically separated meet one another and establish continuing relations, usually characterised by inequality and conflict (Clifford 1997: 6-7). Focus groups are one more addition to this toolkit.

Focus groups are not commonly used in ethnography but they have a particular advantage when studying elites. Elite ethnography is difficult and poses many challenges. We are attempting to enter a closed and secretive world, a hidden world, occupied by people who are more powerful than the researcher. Observing governing elites at work is our preferred research tool but we know from bitter experience that our requests for such access can be denied. Focus groups are another way of gaining access to a group of elite actors, to observe them in action when observation is not possible at the workplace, especially when the relevant individuals are no longer in office, as in this case. So, focus groups are another way of 'being there' and side-stepping the problems of access and secrecy. 
That said, it should be obvious they are not always useful. We are describing their use in the specific setting of governing elites. We are not claiming they are a stand-alone method. So, ideally, we would supplement a focus group with shadowing a CoS. As we will describe below, we do supplement the focus group by including ethnographic interviewing in our battery of tools for collecting data. Moreover, the data generated by focus groups requires an ethnographic sensibility for interpreting the conversations. Ethnography is about recovering meaning and locating that meaning in its broader context; in this case, governmental traditions. So, focus groups are an ethnographic tool because ethnography is now a diverse set of practices linked not by a shared method - participant observation - but by a shared focus on the recovery of meaning.

\section{Prime Ministers' Chiefs of Staff}

$\mathrm{CoS}$ have long been recognised as key players in the Australian core executive. They are appointed by the prime minister because they are known to be loyal and committed. They have a broad remit, but there is no job description. They support both the person who is prime minister and the position that they hold. They run the Prime Minister's Office (PMO) of over 50 staff that operates twenty-four hours a day every day of the year. The CoS tries to ensure the prime minister sets priorities and sticks to them, despite the inevitable crises demanding their time and attention. They help the prime minister to control the agenda, to coordinate policy initiatives, and to keep effective relationships with the cabinet, the ministry, the party room, the media and the public service. They filter who the prime minister sees and how and where they spend their time. Over its forty-year history, the position of $\mathrm{CoS}$ to the prime minister has evolved from an administrative position to one that is now mainly political.

The position of $\operatorname{CoS}$ to the Australian prime minister may be a nodal role in core executive networks but little is known about the nature of the job. How have its occupants 
adjusted to the personalities, preferences and working styles of the prime ministers they have supported? How have they navigated the complexities and pressures of life at the centre of government? How have they dealt with the challenges confronted at different stages of their service?

Our project focused on the beliefs and practices of those who have held the job of CoS, the practices they describe and the stories that they tell about supporting prime ministers. Our shared goal (theirs and ours) was to build the institutional memory of the PMO. We proceeded from the shared premise that what they learned about political leadership and governing might help future CoS. Given the gap between what is written and their first-hand knowledge of life in prime ministers' offices, our study provided an opportunity for $\mathrm{CoS}$ to record in their own words what it was like to 'be there'. The focus groups enabled us to collect their individual and collective stories about the $\mathrm{CoS}$ job.

\section{Focus groups as a tool of ethnographic research}

Focus groups are well established in advertising and marketing research and have been successfully adapted to the social sciences (Agar and Macdonald 1995, Bloor et al. 2001). They involve getting a group of people together to discuss their beliefs and practices. The groups are interactive and group members are encouraged by a moderator to talk to one another. The research does not interview the group members but facilitates their discussion. For Morgan (1997: 2), the 'hallmark' of focus groups is 'the explicit use of group interaction to produce data and insights'. However, there are no guarantees that a group assembled by researchers will promote participation and discussion on a 'defined area of interest in a permissive, nonthreatening environment' (Krueger 2008: 18). So, it is important to prepare carefully for, 
structure, and manage focus group interactions (Morgan 1998; Krueger 1998). How did we prepare for and structure our study of prime ministers' CoS?

\section{Research design}

Our study of prime ministers' CoS used methods drawn from the broad toolkit of interpretive political science. Clearly there are many ways of investigating how $\mathrm{CoS}$ do their job and how and why it changes. In our previous research, our preferred methods have been elite interviews with senior politicians and public servants, and participant observation. From this project's inception we proposed to hold focus groups with people who had served as CoS. It was a central, but not our only, research and data collection strategy.

The research design for our focus groups was adapted from previous studies of Chiefs of Staff in the United States. This research has employed many methods, including elite interviews and focus group discussions (see, for example, Kernell and Popkin 1986; Kumar and Sullivan 2003; Sullivan 2004). Practitioners and scholars have collaborated to build the institutional memory of the White House staff, including the position of CoS. Sharing of insights between those who have worked closely with presidents on both sides of American politics was seen as a way of making the structures of advice and support more professional, and building policy capacity. It was a way of cutting through the opacity and confidentiality that necessarily surrounds a current incumbent. It was a means of building the institutional memory of the presidency and of helping an incoming President to 'hit the ground running' (Sullivan 2004).

Our Australian study had similar ambitions. It aimed to develop a nuanced understanding of the post of $\mathrm{CoS}$ from the perspective of those who had held it. Our proposal was funded by ANZSOG, a consortium of Australian and New Zealand governments and universities. It was established under the Howard government and enjoys strong bipartisan 
support. Key Coalition figures, including David Kemp (CoS to Malcolm Fraser) and Arthur Sinodinos (CoS to John Howard) and senior officials from all levels of government were involved in its establishment, and served on the ANZSOG board. We mention these facts because the support of such a trusted, independent body lent credibility to our research and facilitated access to the $\mathrm{CoS}$. Access is always an issue when doing research involving governing elites. The reputation of the researcher is one factor. The standing of the sponsor is another. We are known to many respondents as 'a safe pair of hands' and ANZSOG is a respected training organization for government. So, we had the essential prerequisites of access and trust.

In late 2009, eleven former prime ministerial CoS spanning governments from Fraser to Rudd came together to take part in two closed, round-table focus group discussions. We called them workshops because focus groups are associated with political campaigning and market research. We wanted to avoid such connotations. With their emphasis on group interaction, our workshops were focus groups in all but name.

Each session aimed to elicit participants' views on the following topics:

- the development and evolution of the job of $\mathrm{CoS}$

- how different individuals approached the task of working with the Prime Minister

- the key duties and responsibilities that they performed

- the challenges confronting the $\mathrm{CoS}$ at different stages of the governing cycle

- lessons that might be passed on to their successors.

In government, it is widely accepted that the first, modern CoS was appointed in 1972. Between then and June 2013, when our study ends, twenty-four individuals held the CoS position (see Rhodes and Tiernan 2014a). Seven attended the first focus group in Canberra on 1 September 2009. A second focus group, held in Sydney on 11 December 2009, was attended 
by four former CoS. Associate Professor Anne Tiernan and Professor Patrick Weller, AO, from the Centre for Governance and Public Policy at Griffith University facilitated the two focus groups. The participants agreed that we could record, transcribe and quote from proceedings. We did not consider it appropriate to ask the serving $\operatorname{CoS}$ to attend the focus group. The sessions that formed the basis for our research were conducted in late 2009.

Since 2009, three individuals have been the Prime Minister's CoS, all for relatively brief periods. To cover these developments, we conducted a further round of interviews with these $\mathrm{CoS}$, and other key respondents; 15 in total. We supplemented the interviews with documentary and other primary sources, and informal conversations. The follow-up interviews were conducted by Rod Rhodes and Anne Tiernan.

\section{Preparing for the focus group sessions}

The interviews with ministers for Tiernan and Weller (2010) gave us access to senior figures from the outgoing Howard and incoming Rudd governments. For the past forty years, Weller has conducted research on ministers, prime ministers and Cabinet. He has established trusting relationships with key members of the Fraser, and Hawke courts, including Dale Budd and David Kemp. Tiernan's (2007) research on ministerial staffers established equivalent relationships with the Hawke, Keating and Howard courts. We had a database of ministerial appointment, background and career data covering the Fraser to Rudd governments. We had a repository of more than 100 interviews with core executive actors that also included the fieldwork by Tiernan (2007) and Tiernan and Weller (2010) on ministerial staffers and ministers respectively. These contacts not only enabled us to conduct further interviews but it also meant we held informal conversations with current and former ministers and ministerial staffers, including former prime ministers' CoS. 
For the focus groups, we obtained the current contact details of the $\mathrm{CoS}$ using public information and snowball sampling techniques. Where necessary, we used our existing networks to find and contact people. We would approach a $\operatorname{CoS}$ through people they knew and trusted. Such networking and snowballing are essential for political scientists attempting to study governing elites.

We wrote formally to key individuals, to invite their participation. Our letter explained that our research approach had been successfully used twice in the United States (see Kernell and Popkin 1986, Sullivan 2004). We developed a background paper that provided a summary of the US research and outlined our aims for this Australian project. We were lucky and our timing was good. Key $\mathrm{CoS}$ who later returned to public life, at the time, were doing other things. ${ }^{2}$ Former $\operatorname{CoS}$ were persuaded our study had merit (Rhodes and Tiernan 2014a: 10). Several accepted immediately our invitation to participate. Others took more prompting, but agreed after being provided more detail and having any questions they had answered.

We took the decision to conduct two focus groups after several weeks of trying unsuccessfully to coordinate the diaries of busy senior figures spread across four Australian capitals, including in one case, Perth. At first, we thought this was less than ideal because the number of participants was seven in Canberra and only four in Sydney. We were concerned the dynamics of so small a group might inhibit discussion or limit the range of topics canvassed. It was not a problem - in Australian parlance, 'no worries' - but we discuss group dynamics in more detail below.

The Canberra focus group was an evening meeting. Discussions were conducted in two sessions, each of around two hour's duration. We had a break of about 45 minutes for drinks and refreshments while the boardroom was set for a working dinner. Sydney was a morning meeting, commencing with discussions over breakfast and running through until lunch-time. 
Each focus group lasted roughly four hours. A photographer took pictures of the group and individuals simply to illustrate the planned book. It was our judgement that videotaping the proceedings would be a step too far. We settled for recording and transcribing the sessions - an approach that Bloor et al. (2001: 3) consider the most rigorous analytical strategy for focus group research.

\section{Managing group dynamics}

Morgan (1997: 15) argues that focus groups' reliance on interaction in the group to produce data is a key strength. He notes participants' comments on each other's experiences and opinions are 'a valuable source of insights into complex behaviours and motivations'. But much depends on the design and management of focus groups. They are a method for gathering research data and are created for a well-defined purpose (Morgan 1998). With this in mind, we tweaked the focus group methodology by developing procedures we judged were suited to working with members of the governing elite. A week before the workshop session, we circulated a list of research questions to guide discussion (see Rhodes and Tiernan 2014a). We asked each $\mathrm{CoS}$ to open discussion on a specific question that was assigned in advance. We proceeded broadly in chronological order of service. These procedures are not the norm in focus groups but worked well, especially as these elite respondents are used to driving their own agendas. The moderator's key tasks were to ensure that all topics were covered and that the discussion remained focused.

A focus group is a constructed social situation, where the informants share information about their practices with other participants. On this occasion, the participants did not hold different positions in the organization. None were currently a CoS. None were still in government. The members were alike; there were no differences of rank, no opportunity to exert authority one over the other and little point in playing power games beyond gratifying 
their own egos. If anyone's ego required such a massage, it was not obvious to us or to the other participants who would have briskly put an end to any such behaviour. Nor were there any obvious attempts to be liked by or to please the moderators.

We explained that the study would be conducted following the University's research ethics protocols. Coupled with their prior experiences of talking to us, they were confident that no ill-judged remark would return to haunt them later. We agreed quotations would be cited and attributed only with their express permission. It is our judgement the $\mathrm{CoS}$ came to the workshops as a group of like-minded colleagues willing and able to share their experiences openly. Our aim was not to find disagreements, but to identify common ground from which to draw lessons.

We had been concerned the dynamic among a diverse group of former political enemies, factional and professional rivals might inhibit discussion of sensitive issues. However, the everyday demands of the job meant they had much in common. Any lingering tensions or partisan differences quickly dissipated. Of course, possibly, disagreements and power plays could have elicited more 'accurate' and interesting information. Such behaviour could also have disrupted the group and ended cooperation and sharing.

We encountered two issues in managing the focus groups. First, we discovered after the meetings that two separate focus groups cemented the participation of one of the $\mathrm{CoS}$ who was not keen on being in a session with a former colleague. The second issue manifested as a power play with us. Before discussion started, one participant contested our account of how the CoS' job had developed in our Background Paper. He questioned our decision to commence the study with the Whitlam government, arguing there was an extensive prehistory under earlier governments. He wanted assurance that we would address the period before 1972 and give due attention to the Menzies and later Coalition governments (see Rhodes and Tiernan 2014a: 
chapter 3). This exchange can be read as a partisan point, but we see it more as a test; a clear if mild reminder of the power relativities between ourselves as researchers and the CoS. How we responded was the critical issue. We explained our rationale for taking 1972 as our starting point, and agreed to take account of his concerns and any other comments and suggestions from participants. Seemingly appeased, and with the first $\mathrm{CoS}$ ready to open debate, the focus group proper began. After this early awkwardness, we had 'no worries' because they settled into a free and frank exchange of views. At times, we were conscious that we were not in control of the group. Some mild degree of anarchy is to be expected in any group indulging in openended discussion. Their freewheeling conversations demonstrated they were at ease; a gratifying outcome.

Our opening question was: 'What is the job of the Chief of Staff? What are its duties and responsibilities?' CoS responses to this question illustrate the value of focus groups for ethnographic research in political science. As invited, David Kemp, widely credited with helping Malcolm Fraser develop the framework for a significantly upgraded Prime Minister's private office, outlined how Fraser's view of the CoS position evolved during his time in office. Kemp described the key developments and events that led to a broadening of the CoS' tasks. Dale Budd confirmed and elaborated this account. He compared the different ways each approached the job of meeting their prime minister's needs. Graham Evans (Hawke) and Don Russell (Keating) commented on the long-term impact of Fraser's vision and views had on the CoS position. Such interaction produced a far richer account of how the PMO and the CoS developed than would have been possible through semi-structured interviews with individual CoS.

Other questions were organised chronologically. Participants explored challenges confronting the $\operatorname{CoS}$ at key stages of the governing cycle. Thus, the group discussed issues of 
transition, learning to govern, crises and unexpected events, facing re-election, renewing the mandate, and facing defeat. All yielded valuable insights and, at times, amusing exchanges. There was much laughter as individual's stories bumped into one another. For example, David Epstein (CoS to Rudd) thought his predecessor, Nicole Freely (CoS to Howard), deliberately ignored the public service, when she was simply unaware that they would (say) deal with the voluminous correspondence for her. It was that simple. Human frailty is as powerful an explanation of what was going on as political calculation.

Ethnography is a 'rather uneasy combination of involvement and detachment' (Fox 2004: 4). Because we are detached, we are 'strangers', not members of the group, so, in seeking to understand their world, we expect to be unaware of several issues. They emerged spontaneously from the CoS' reflections. For example, we learned about the importance of 'feeding and watering' prime ministers and protecting their health by carefully monitoring the safety of food, particularly when they travel overseas. As the following exchange shows, the Canberra focus group developed a vivid word portrait of Dr. Graham Killer, Surgeon General for the Department of Veterans' Affairs, who has been personal physician to prime ministers since 1991. Here, as elsewhere, the lack of space means that we illustrate a general point of agreement in the group with a story from one or two individuals.

Geoff Walsh: Paul [Keating] wasn't too fussy labout eatingl, except when we went [on an overseas visit]. We had a doctor who travelled with us-the improbably named Dr. Killer.

Grahame Morris: He is still the man.

Geoff Walsh: He hasn’t lost a Prime Minister yet [laughs]. Anyway, Dr. Killer went to inspect the kitchen before the state dinner ... He came back ashen-faced and 
said, 'There's a toilet in the middle of the kitchen. My advice is don't eat anything.' So Paul spent the night with the menu in front of him and basically dodging, because he had a view that you could pick up hepatitis or something. That would be the end of your career.

Grahame Morris: It's still the standard advice of Graham Killer now: anything that might have been near water, lettuce or anything, don't eat it. Brush your teeth out of bottled water or whiskey. So, he's still giving the same advice and he's still keeping PMs alive.

Sydney focus group participants added their experiences after we recounted our concern that 'Dr. Killer' might have been a nickname and sought to clarify his status:

David Epstein: Dr. Killer and his mystery bag of drugs.

Allan Hawke: He's been the one constant lin the PMOJ throughout all of this. Been there forever. You should interview him I reckon.

Nicole Feely: You really need it don't you? A great big bag.

This exchange is significant for two reasons. First, in this degree of detail, academics know so little about government. The $\mathrm{CoS}$ take such practices for granted and the researchers don’t know what they don't know, so cannot ask relevant questions. Group discussion takes you down illuminating byways that would never occur in individual interviews. It is a clear illustration of why focus groups are more revealing than individual interviews (Bloor et al. 2001). Second, the story illustrates the lengths to which the $\operatorname{CoS}$ will go to protect their prime minister. There is no partisan dimension to their practices here, just a shared concern for the prime minister's well-being. 
There were many such exchanges. Among the most revealing for our project was the participants' insistence that a broad connotation of political is essential to understanding the support needs of present-day prime ministers:

David Kemp: I think it's also important to read the word 'political' as having broad meanings. There's a tendency to think political equals elections, equals campaigning, equals voting. But that's not right. Political involves managing the legislation in the Senate and the sensitivities of the minor parties, political and what's Senator [Harradinel going to do $9^{3}$ Political means how is the backbench going to feel about this? Are they going to support this course of policy? Political means, what are you picking up about how this policy is working? Or political could mean are our priorities right at the moment or do we need to shift them in some way?

Political can mean what are the consequences of this political event and how do you read that? So there's a lot of political expertise there, which has to do with effective government, I would say. I think that without the political being dominant, you don't get effective government.

Now that doesn't mean that one political aspect, one aspect of being political-campaigning-needs to dominate everything. I think that would be bad. But being politically effective means managing the government properly because all these issues of leadership and values and the different groups that have to be coordinated, that's all political. They are things that were not properly done in my view before 1975 or 1972, whatever point you'd like to take. 
Graham Evans: I agree with the points that David /Kempl has made. There's a significant difference between a view of political which is a narrow one, which I would say is party political, and a broader view that relates to implementation of policy. Advising on the context and consequence of policy is central to the role of prime ministerial offices, so the Prime Minister's policies have the best chance of being agreed to and implemented.

We use one long quote from a single individual but his comments were accompanied by much group nodding. His views were widely shared. Indeed there wasn't a single voice of dissent, just elaboration and illustrations of the points made.

\section{Analysis and interpretation}

The two focus groups yielded nearly nine hours of qualitative data; 230 pages of transcripts in total. We checked the transcripts against the audio and where necessary, made corrections. Such a valuable data set warrants a careful curator. We read the transcripts separately with an agreed codebook modified from our earlier work on governing elites (see Rhodes 2011; Tiernan and Weller 2010). We compared our results, but disagreed more over the severity with which we edited the transcripts for inclusion in the books than about issues of substance. Our dilemma was how best to organise the rich insights and institutional memory generated by the $\mathrm{CoS}^{\prime}$ individual and collective contributions ${ }^{4}$

We took the organising concepts for telling their stories from Bevir and Rhodes' (2003 and 2006). Their interpretive approach shifts analysis away from institutions, functions and roles of mainstream public administration to the actions and practices of interdependent actors. To understand actions and practices, we need to grasp the relevant meanings, the beliefs and preferences of the people involved. An interpretive approach seeks to understand the webs of significance that people spin for themselves. It provides a 'thick description' in which the researcher writes his or her construction of the subject's constructions of what the subject is up 
to (adapted from Geertz 1993: 9). So, the task is both to unpack the disparate and contingent beliefs and practices of individuals through which they construct their world; then to identify the recurrent patterns of actions and related beliefs; the shared beliefs. So, in interpreting our focus group data, we focused on the shared beliefs and practices of the $\operatorname{CoS}$.

\section{The case for focus groups}

Commenting on our draft manuscript, a colleague remarked: 'I think people tell you a lot more in interviews than probably they tell you in the focus group setting'. We do not agree that focus groups are inferior to semi-structured interviews as a method for data collection. Of course, interviews can be revealing in the hands of a skilled interviewer. Although we are experienced interviewers, we have good and bad interviews. All elite interviewers know the public servant and minister who can negotiate such an encounter with ease. They can 'talk for an hour without saying anything too interesting' (Rawnsley 2001: xvii-xviii citing an interview with Robin Cooke, former British Foreign Secretary). Some days the elite interview resembles nothing more than a confining ritual. Moreover, interviews never last a day.

A good focus group is revealing because the 'focus' is on interaction and conversation, not the single interviewee. The interaction between people clarifies the meaning of practices and events. Morgan (1997) highlights the potential for insights from focus groups, especially when part of a multi-method study (also see Bloor et al. 2001). And our study used several methods: in-depth interviewing, official documents, biographies, memoirs and diaries, informal conversations, as well as focus groups. So, we could cross-check data from multiple sources.

Agar and MacDonald (1995: 78) suggest that ethnography provides 'broader frames of interpretation' for focus group data (Agar and MacDonald 1995: 85). Our interpretive theory provides the conceptual tools for evaluating the significance of focus group data. However, 
Agar and MacDonald (1995) stress that the researcher must have prior knowledge of the 'shared folk models' of focus group participants to assess discussions and interpret their meaning. Our combination of skills and experience is worth noting here. We both have extensive experience of research on governing elites in Australia and Britain. We are familiar with the folk theories of government in both countries. So, we have the requisite broader frame of interpretation to identify and evaluate the issues and themes in the conversation. That frame is the Australian Westminster tradition about executive government.

All CoS share the beliefs and practices of the Westminster tradition about collective cabinet government, ministerial responsibility, a constitutional bureaucracy, and parliamentary sovereignty (Rhodes 2005; Rhodes et al. 2009). They had a shared narrative about what they were doing, what prime ministers needed, and how they worked. The focus groups revealed the common ground between them. For example, Grahame Morris explained that 'Howard] used to place great importance on the party room meeting, on the Cabinet, on the leadership meetings and on the tactics meeting. So you sort of had three big touch points most days, or certainly most weeks with the colleagues.' The CoS agreed that their prime ministers had to manage their dependence on their ministerial colleagues, cabinet and the party in parliament; all cornerstones of the Australian governmental tradition.

Focus groups have some singular advantages when studying closed elite groups. First, group discussion provides more illuminating insights because participants open up more topics than would occur in an individual interviewee.

Second, the interaction between people clarifies the meaning of practices. Focus groups provide opportunities to develop a detailed understanding of participants' beliefs and actions, and to compare experiences and to encompass a diversity of views. 
Third, like other forms of ethnography, focus groups make tacit knowledge explicit. They produce context-specific qualitative data on complex and sensitive issues. For example, supporting the prime minister did not refer simply to the official role but also to the person; to family, health, and eating overseas.

Fourth, focus groups can produce 'relevant' knowledge and our work was seen as relevant by the CoS. We asked the former them to reflect on mistakes and lessons learned and to write a memo for their successor. We asked them what advice and wisdom they would pass on. We distilled their reflections into lessons, using their words and phrases (see Rhodes and Tiernan 2014b). This approach can be summarized as the '3Rs' of recover, recount and review. The aim is to recover the stories we are told by politicians and public servants. We systematised these accounts, telling our version of their stories, and recounted them. Our version was jointly reviewed to identify inaccuracies, divergence, and lessons. The aim was a fusion of horizons that covered both agreement and where we agreed to disagree. Both outcomes were reported. In effect, the '3Rs' constitute a technology that can derive practical lessons from lived experience; an interpretive equivalent of evidence-based policymaking.

\section{The case against focus groups}

Focus groups also pose some specific problems. First, the qualitative data can be inaccurate and contested. For example, Nicole Feely recollected that Mike Keating (Head of PM\&C) was not available to advise the new prime minister, John Howard, on the transition to government. Others contradicted her account. We resolved the issue by circulating all quotes from the transcripts to all participants. In effect, the participants checked one another's version of events. We also did follow-up interviews with senior politicians and public servants who worked with the CoS. However, our task was to collect their stories, and even when there are competing stories, the lesson is obvious; ensure the Head of PM\&C is available to advise the 
prime minister during the transition. Moreover, focus groups were but one of our set of methods. We compared the version of events from different data sources. Ultimately, of course, the researcher's judgement will prevail. It will be our version of their story, and we will choose between the competing versions by deciding which is most plausible because it marshals the more convincing evidence.

Second, the data can be hard to analyse. Analysis hinges on the research question and the organising concepts of the researcher. In our case, we used an interpretive approach rooted in the work of Bevir and Rhodes (2003 and 2006). For example, we interpret the practices of CoS by ascribing beliefs to them. Practices presume apt beliefs, and beliefs do not make sense without the practices to which they refer. The beliefs of the $\mathrm{CoS}$ are about orderly process, not substantive political ideas and specific policies. The core belief is supporting and protecting the prime minister. The prime minister's every wish is their command, even if the CoS pushes back on occasion. Of course, the prime minister's wish might be for policy advice or acting as the keeper of the government's narrative. Such work is done at the Prime Minister's bidding, not on their own initiative. Indeed, the Prime Minister comes before party, government and the national interest.

Third, there are practical problems. Recruiting a sample of respondents willing to participate in discussions in a group setting is an obvious one. Managing focus group interactions is another. Risks include a zealous moderator stifling the flow of group discussions or for conversation to be dominated by a few participants. The moderator of discussions among governing elites must be prepared to negotiate its personal dynamics. Detailed knowledge of political context, events and personalities is needed if the researcher is to understand and interpret discussions and exchanges between participants. The moderator must 
have patience and tolerate the at times messy exchanges. Focus groups can be 'untidy'. In seeking some order in the discussion, don't expect and don't want to be liked.

Fourth, we agree that questions remain about the efficacy of focus groups if they are used as a stand-alone method in the social sciences (Bloor et al 2001; Morgan 1997). We did not use it as a stand-alone method. We used several methods so we could cross-check our data (see Rhodes and Tiernan 2014a). Using multiple sources of data gives many opportunities to cross-check the data and form a judgement about its reliability.

Finally, researchers need to recognise that elite actors are both accustomed to and skilled in providing 'strategic' responses and directing discussion in preferred directions. Simply, 'the research participants are more powerful than the researchers' (Shore and Nugent 2002: 11). They control access and exit. They end interviews, refuse permission to quote interviews, and deny us documents. They can control what we see and hear. These comments have much force when they refer to elite interviewing or observation (Rhodes 2011, Rhodes et al. 2007). However, the simple fact that a focus group is a 'group' means those individual strategic responses are subject to group scrutiny. To be effective, such responses need group agreement. Moreover, we note the possibility of strategic responses. We do not suggest they are the norm or even common, only that they occur. In this case, the group discussion was not arbitrarily ended. We published two books. We have permission to name our sources.

\section{Conclusion}

This paper is about one method, not about our theoretical approach or the substantive findings of our fieldwork. We have described how we have tweaked the focus group methodology for working with elite groups. We draw three conclusions. First, focus groups are a useful tool for recovering the beliefs and practices of governing elites but, second, they are not 
a stand-alone tool. They are part of a larger toolkit that encompasses in-depth interviewing, official documents, biographies, memoirs and diaries, informal conversations, as well as the queen of ethnographic methods, observation. Finally, the analysis must be located in a broader framework. We do not claim that our interpretive approach is the only way to analyse focus group data. We do insist that any attempt to analyse that data must have an equally explicit theory.

The CoS tell a tale of contingency; of helping the prime minister -the office and the person - to cope and survive the myriad pressures and inherent dependencies of political leadership. We know the CoS speak a shared, sometimes puzzling, language. Their words tell a tale of contingency and personalities:

it was extraordinarily chaotic. You know, you have this impression that it's all ordered and disciplined and it all happens in this way, all the right people are consulted et cetera. Often it's not like that at all. Often it depends-and this is no surprise-it depends so much on personal relationships. When they're in good stead and good standing, things happen in a different way as compared to when they're fractured (Allan Hawke when CoS to Paul Keating)

It is a closed world. Still, they gave us the opportunity to record their beliefs and practices. They talked to us about many matters that simply do not get into academic books, journals or the media. Maybe we asked leading questions. Perhaps it was just the way conversation flowed. Nonetheless, we are confident the focus groups provided a context in which much tacit knowledge was made explicit. 


\section{References}

Agar, M. \& MacDonald, J. (1995). 'Focus groups and ethnography', Human Organization, 54 (1): 78-86.

Auyero, J. and Joseph, L. (2007). 'Introduction: Politics under the Ethnographic Microscope', in Joseph, L. Mahler, M. and Auyero, J. (Eds.) New Perspectives on Political Ethnography, New York: Springer: 1-13.

Bevir, M. and Rhodes, R.A.W. (2003). Interpreting British Governance. London: Routledge.

Bevir, M. and Rhodes, R. A. W. (2006). Governance Stories. London: Routledge.

Bloor, M., Frankland, J. Thoms, M. and Robson, K (2001). Focus Groups in Social Research. Sage, London

Clifford, James (1997), ‘Four Northwest Coast Museums: Travel Reflections’, in his Routes: Travel and Translation in the late Twentieth Century, Cambridge: Harvard University Press, 107-46.

Collini, S. (2001). 'Postscript: Disciplines, Canons, and Publics; the History of "The History of Political Thought" in Comparative Perspective', in D. Castiglione and I. HampshireMonk (Eds.), The History of Political Thought in National Context. Cambridge: Cambridge University Press: 280-302.

Denzin, N. K. and Lincoln, Y. S. (2011) [1994]. 'Introduction: the discipline and practice of qualitative research', in N. K. Denzin, and Y. S. Lincoln (Eds) Handbook of Qualitative Research, 4th edition. Sage: London: 1-19. 
Fox, K. (2004). Watching the English. The Hidden Rules of English Behaviour, London: Hodder and Stoughton.

Geertz, C. (1993) [1973]. 'Thick Descriptions: Towards an Interpretive Theory of Culture', in his The Interpretation of Cultures. London: Fontana: 3-30.

Hammersley, M. and Atkinson, P. (2007) [1983]. Ethnography: principles in practice, $3^{\text {rd }}$ edition. Routledge: London.

Howard, John (2010). Lazarus Rising. Sydney: Harper Collins.

Kernell, S. \& Popkin, S.L. (Eds.) (1986). Chief of Staff: Twenty-five Years of Managing the Presidency. University of California Press: Berkeley \& Los Angeles.

Krueger, R. A. (1998). Moderating Focus Groups. Focus Group Kit 4. Sage: Thousand Oaks, California.

Morgan, D. (1997). Focus Groups as Qualitative Research, 2nd edition. Sage Publications: London.

Morgan, D. (1998). Planning Focus Groups. Focus Group Kit 2. Sage: Thousand Oaks, California.

Pollitt, C. (2008). Time, Policy, Management. Governing with the Past. Oxford: Oxford University Press.

Rawnsley, A. (2001). Servants of the People: The Inside Story of New Labour. Revised edition. London: Penguin Books.

Rhodes, R. A. W. (2005). 'Australia': The Westminster Model as Tradition', in Patapan, H., Wanna, J. and P. Weller (Eds.), Westminster Legacies: Democracy and 
Responsible Government in Asia, Australasia and the Pacific. Sydney: University of New South Wales Press: 129-52.

Rhodes, R. A. W. (2011). Everyday Life in British Government. Oxford University Press: Oxford.

Rhodes, R. A. W. (2013). From Prime Ministerial Leadership to Court Politics', in Paul Strangio, Paul 't Hart and James Walter (Eds.), Prime Ministerial Leadership: Power, Party and Performance in Westminster System. Oxford: Oxford University Press 2013: 31833.

Rhodes, R. A. W. (2015). 'Ethnography', in Mark Bevir and R. A. W. Rhodes (Eds.), The Routledge Handbook of Interpretive Political Science Abingdon, Oxon: Routledge: forthcoming.

Rhodes, R. A. W. and A Tiernan (2014a). Lessons in Governing: A Profile of Prime Ministers' Chiefs Of Staff. Carlton, VIC: Melbourne University Press.

Rhodes, R.A.W. and Tiernan, A. (2014b). The Gatekeepers: Lessons from Prime Ministers' Chiefs of Staff. Carlton, VIC: Melbourne University Press.

Rhodes, R. A. W., Paul 't Hart and M. Noordegraaf (2007). 'So What? The Prospects and Pitfalls of Being There', in R. A. W. Rhodes, Paul 't Hart and M. Noordegraaf (Eds.), Observing Government Elites: up close and personal. (Houndmills, Basingstoke: PalgraveMacmillan, 2007): 206-33.

Rhodes, R. A. W., Wanna, J. and Weller, P. (2009). Comparing Westminster. Oxford: Oxford University Press. 
Shore, C. and Wright, S. (Eds.) (1997), The Anthropology of Policy. Critical Perspectives on Governance and Power. London: Routledge.

Shore, C. and Nugent, S. (2002). Elite Cultures. Anthropological Perspectives, ASA Monographs 38. Routledge: London.

Sillitoe, Paul. (2006). 'The Search for Relevance: A Brief History of Applied Anthropology'. History and Anthropology, 17 (1): 1-19.

Sullivan, T. (Ed.) (2004). The Nerve Center: Lessons in Governing from the White House Chiefs of Staff. College Station, TX: Texas A\&M Press:

Tiernan, A. (2007), Power without Responsibility: Ministerial Staffers in Australian Governments from Whitlam to Howard. UNSW Press: Crows Nest, NSW.

Tiernan, A. \& Weller, P. (2010). Learning To Be a Minister: Heroic Expectations, Practical Realities. Melbourne University Press: Carlton, Vic.

Wulff, H. (2002), 'Yo-Yo fieldwork: mobility and time in multi-local study of dance in Ireland', Anthropological Journal of European Cultures 11: 117-36.

\section{Notes}

${ }^{1}$ We must note two partial exceptions. First, the Public Administration Theory Network (PAT-Net) has an annual conference and its own journal, Administrative Theory \& Practice. It is associated with postmodernism and critical theory. Second, the Interpretive Policy Analysis network also has its own annual international conference and associated journal, 
Critical Policy Studies. Both draw on ethnography. Both are examples of 'patterned isolationism'; that is marginalised areas of inquiry which do not 'fit' the disciplinary mainstream. At best, these alternative theories and methods sit alongside, and at worst outside, established disciplines and departments (Collini 2001: 299).

${ }^{2}$ For example, Arthur Sinodinos had left the CoS position in December 2006. He was working in finance and banking and was serving on the ANZSOG Board. He became a Senator for New South Wales in September 2011, filling a casual vacancy. Similarly, Don Russell (CoS to Paul Keating) was working in the financial services sector in Sydney when approached to participate in our study. He was appointed Secretary of the Department of Innovation, Industry, Science and Research in 2010. It is unlikely either would have agreed to participate had they held public positions at the time.

${ }^{3}$ Australian government has a House of Representatives and a Senate. The latter can block legislation initiated by the House. When he was Prime Minister, John Howard did not control the Senate until his final term. During his first term, he relied on support from the Australian Democrats and independents, including Independent Senator for Tasmania, Brian Harradine (see Howard 2010: 241-3).

${ }^{4}$ For lack of space we cannot discuss institutional memory here but for more detail see Rhodes 2011 and Rhodes and Tiernan 2014a. See also Pollitt 2008. 